\title{
Evaluating the Technology-Enhanced Flipped Classroom Through the Students' Eye: A Case Study
}

\author{
Kevin Fuchs
}

Faculty of Hospitality and Tourism, Prince of Songkla University, Thailand

aj.kevin.fht@gmail.com

\section{ABSTRACT}

Emergency remote teaching (ERT) during the unprecedented global pandemic, COVID-19, identified the pressing need for innovative teaching methods that support and foster technology-enhanced active learning through the distance education paradigm. Distance education is not a new phenomenon, while the flipped classroom concept is also a well-researched method. However, there have been rather few studies about the flipped classroom (FC) approach in higher education with the support of technology. This study contributes by critically exploring how full-time distance students perceived the usefulness of the Technology-enhanced Flipped Classroom (TEFC) approach to support their graduate studies. A series of semi-structured interviews $(n=7)$ collected the empirical data for this qualitative method of inquiry. Moreover, teaching materials were used for the data collection, while the interviews were preceded by a preliminary observational study in a TEFC in a STEM graduate-level course. Through thematic analysis, three major themes were identified that offered a broader insight into the students' perspectives concerning the benefits and challenges of the TEFC concept. The themes were sentimental involvement, technical FC design, and peer-communication. The primary finding revealed that the students perceived the discussion-based sessions in the TEFC to have enabled them to foster their knowledge transfer. It was also perceived as particularly positive in its ability to contribute to and influence the discussion flow. These validated earlier claims concerning a positive perception of the TEFC concept in the formal learning process. This research discovered that TEFC is a viable tool to support learning in a pandemic situation by empowering students and facilitating active learning through information and communication technologies (ICT).

Keywords: Technology-enhanced Learning (TeL), connectivism, active learning, flipped learning

Cite this article as: Fuchs, K. (2021). Evaluating the Technology-Enhanced Flipped Classroom Through the Students' Eye: A Case Study. Journal of e-learning Research, 1(2), 13-21. https://doi.org/10.33422/jelr.v1i2.54

\section{Introduction}

\subsection{Constructivism as a Facilitator for Active Learning}

To better understand the technology-enhanced flipped classroom method (TEFC) and its role in higher education, it is important to review the fundamental educational theory from which the flipped classroom is derived. The social learning aspect, through interaction, communication, and socialization with peers, is a large differentiator between the educational learning theories - namely constructivism and instructivism. Constructivism emphasizes that students are supposed to share their own knowledge as a prerequisite to building new knowledge or changing the students' perceptions of particular information (Dewey et al., 1999;

(C) The Author(s). 2022 Open Access. This article is distributed under the terms of the Creative Commons Attribution 4.0 International License, which permits unrestricted use, distribution, and redistribution in any medium, provided that the original author(s) and source are credited. 
Crosslin, 2016). Instructivism views education as teacher-centered and believes in the hardwiring of knowledge through the consistent repetition of information (Piaget, 1976; Dewey et al., 1999).

\subsection{Why Do We Need to Flip?}

It is widely recognized that the relevance of educational transformation is imminent and that flipped classrooms can offer a partial solution to the challenging task of providing quality education while coping with the increased number of students in distance education (Kim et al., 2014; Olaniyi, 2020). McLaughlin et al. (2014) claimed that, namely, critical thinking, complex reasoning skills, and written communication were at the core of most underdeveloped competencies in higher educational institutions. According to Li et al. (2019), this was still a valid claim. There were advantages in that the flipped classroom concept can contribute to the effort to enhance student engagement and, respectively, improve learning outcomes (Bishop and Verleger, 2013; Zainuddin and Perera, 2019). In addition to the anticipated benefits of applying the flipped classroom method, Davies, Dean, and Ball (2013) examined the underlying methods with the objective of identifying how Information and Communication Technology (ICT) can contribute to such a learning effort.

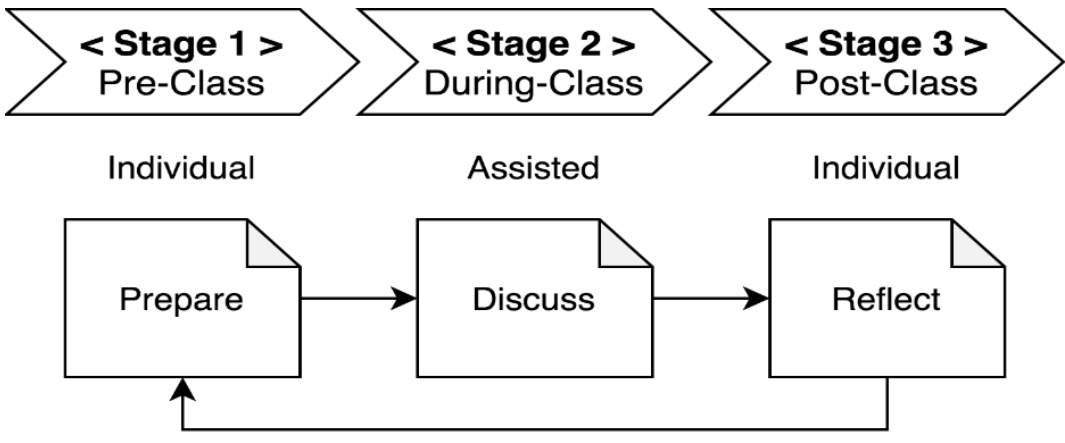

Figure 1. A simplified flowchart of the technology-enhanced flipped classroom Source. Own figure adapted from Mukherjee et al. (2017)

Information and Communication Technology (ICT) played a critical role in providing an effective learning environment for the participants. It can be considered the enabler for the flipped classroom concept for distance students. There was a consensus that the video conferencing application Zoom was primarily used for the during-class stage of the flipped classroom; the participants perceived Zoom as beneficial to their learning based on its ease of use and the absence of barriers in connecting to the class and with their peers (Figure 1). For content sharing, Google Suites applications were utilized. The participants stated that Google Slides, Google Documents, Google Drive, and Google Hangout were used due to the ability to access them easily from any remote location.

The Learning Management System (LMS) that was used in this flipped classroom course was Moodle; students stated that it was only utilized to access recorded lectures for the pre-class and to submit assignments after the post-class. Melzer (2019) claimed that LMS is intended to offer a one-stop solution for students and teachers alike, enabling them to access information and communicate on the same platform. However, none of the participants preferred to communicate through the LMS platform with peers or the teacher. The participants' comments 
- that Zoom and Google Suites were utilized due to their ease of use and remote access - could offer a possible explanation as to why Moodle was not utilized for that same purpose.

\section{Methodology}

\subsection{Sample}

In order to examine how graduate students perceived the technology-enhanced flipped classroom (TEFC) method, the following qualitative research paradigm was developed. The data was collected through semi-structured interviews with graduate students $(n=7)$ that were enrolled in a Master of Science program at the time. The sample size was representative of $20 \%(n=7)$ of the total student enrollment $(n=35)$ in the graduate course that was conducted as a flipped classroom. The students were degree students at Linnaeus University in the south of Sweden that had conducted their entire degree as distance study. Moreover, the participants were randomly selected and invited to participate in the interviews. Five female participants and two male participants contributed to the data collection. (Table 1).

\subsection{Data Collection}

Seven semi-structured interviews were conducted through online video conferencing to collect the necessary data in order to examine the perspectives of graduate students concerning the technology-enhanced flipped classroom (TEFC) method. Data collection was carried out in the first half of 2020 at Linnaeus University in Sweden at the Faculty of Technology. The primary data collection was preceded by a non-participant observation of the author. The author was given full access to the course material and observed a TEFC discussion through Zoom in order to enhance the quality of the interview questions. Necessary adjustments were made based on the observation and a suitable questionnaire was developed for the semi-structured interviews (Appendix 1).

Table 1.

Demographics of the participants

\begin{tabular}{lccc}
\hline Participants $(\mathbf{n}=\mathbf{7})$ & Category & Absolute & (Percent) \\
\hline \multirow{3}{*}{ Gender (Sex) } & Male & 2 & $(28,6 \%)$ \\
& Female & 5 & $(71,4 \%)$ \\
& Other & - & - \\
Age Range & $21-29$ years old & 2 & $(28,6 \%)$ \\
& $30-39$ years old & 2 & $(28,6 \%)$ \\
& 40 years or above & 3 & $(42,8 \%)$ \\
Completed & Other & - & - \\
Education & Bachelor's Degree & 3 & $(42,8 \%)$ \\
& Master's Degree & 3 & $(42,8 \%)$ \\
Geographical & PhD Degree & 1 & $(14,4 \%)$ \\
Location & Other & - & - \\
& Sweden & 2 & $(28,6 \%)$ \\
SOurce. & EU Country & 5 & $(71,4 \%)$ \\
\hline
\end{tabular}

Source. Based on empirical data collection 


\subsection{Data Analysis}

The nature of the semi-structured interview was a series of open-ended questions that aimed to gain a more comprehensive insight into the participants' perspectives on the technologyenhanced flipped classroom. With the consent of the participants, the interviews were audiorecorded and later transcribed. Moreover, the transcripts were used for thematic analysis. The data was converted to codes and later to themes which are presented in the proceeding chapters (Creswell \& Creswell, 2017).

\section{Findings}

In anticipation of the open-ended questions, the participants were first asked to rate their perceived level of involvement in the discussion sessions of the TEFC. Hereafter, the students offered pre-coded answers based on a Likert-type scale. Three participants stated that they were very active in the TEFC sessions, wherein one was somewhat active, one felt neutral about it, and two participants perceived themselves as passive participants of the discussion-based sessions.

All participants had a common consensus about the usefulness of the flipped classroom method. Amongst the stated benefits were active learning, sophisticated discussions, more interesting content, discussions as a learning method, and motivation to prepare in advance (Table 2).

Table 2.

Perceived benefits of the Technology-enhanced Flipped Classroom

\begin{tabular}{l} 
Perceived benefits of the Technology-enhanced Flipped Classroom \\
\hline Learn from peers; Motivation to prepare in advance; Ability to watch, rewind take breaks \\
Possibility to actively contribute \\
Preparing in advance leads to better learning outcomes \\
Prepare in advance and the ability to have a more sophisticated discussion \\
Can listen to what peers think about a specific topic \\
More interesting content when discussing with others
\end{tabular}

Source. Based on empirical data collection

The findings concerning communication revealed that students had a diversified perspective. However, they generally perceived the sessions as positive and interactive. It was stated that a series of sessions would be required to build a foundation needed to communicate effectively and share opinions. In particular, findings that related to positive perceptions of the participants included the ability to learn from peers, a higher motivation level to prepare for the class compared to traditional learning, and the ability to actively contribute to the discussion and therefore influence the learning outcomes of others.

"The discussion about what you have seen, read, or looked at in the recorded lecture is the most valuable learning session."

Furthermore, it was stated that benchmarking own knowledge to others provided an interesting insight into one's ability and level of knowledge by listening to a peer discussion in a passive role. The negative comments that were made can be viewed as a possible limitation of the flipped classroom based on the experiences of the participants. These primary comments that were made related to the initial hurdle of speaking up as a result of not knowing each other. Also, the requirement of a quiet learning environment was mentioned if the participants wanted to actively 
participate in the discussion. Moreover, participants stated the avoidance of responsibilities by peers as a possible shortcoming (Table 3 ).

"I think it is because we did not really get to know each other beforehand. I think it could also be cultural. [...] It is really easy for others to hide behind anonymity and take no responsibility for their tasks."

Table 3.

Perceived deficiencies of the Technology-enhanced Flipped Classroom

\begin{tabular}{l} 
Perceived deficiencies of the Technology-enhanced Flipped Classroom \\
\hline Less flexibility in a noisy environment \\
The topic is new and felt insecure to answer in front of peers \\
Initial communication barrier \\
Avoidance to take responsibility for learning tasks and assignments
\end{tabular}

Source. Based on empirical data collection

It can be stated that the majority of comments that were made by the participants with regards to their perceptions of the TEFC were of a positive nature. All of the participants commented that they preferred the flipped classroom teaching compared to traditional lecturing. Preparation in advance and discussion-based sessions were primarily mentioned by the participants as positive contributors. Many of the participants mentioned that these means had a positive effect on achieving their learning outcomes; some also mentioned that without the TEFC, they would not be able to achieve the same learning outcomes and knowledge transfer.

Essentially, three main advantages can be outlined based on the analysis of the empirical findings. Participants repeatedly stated that (1) the discussion assisted them to foster knowledge transfer. Despite the fact that the participants had different levels of participation in the discussion according to their perceptions, all participants agreed that the discussion amongst peers was helpful to advance their knowledge and reach the learning objectives of the course. Furthermore, the participants stated that (2) the ability to contribute and influence the discussion and affect their learning outcomes was perceived as particularly positive. Lastly, (3) another main advantage of the flipped classroom sessions for distance students was the flexibility to participate in the active sessions from remote locations and incorporate the course into their daily routine.

Although the overall perception of the TEFC method was positive, there were also shortcomings addressed by the participants. The participants stated that (1) there was a limitation in the use of the TEFC method for a one-off session. The initial barrier to communicate required a series of meetings to engage in a meaningful discussion. Furthermore, (2) the teacher was needed and required as a facilitator to spark initial discussions while participants were still getting to know each other. However, the teachers' involvement faded as the sessions progressed. Lastly, (3) a limitation was attempting to actively take part in the discussion when situated in a noisy environment, as this would not only disrupt own learning, but also affect other participants if there were noise disturbances.

\section{Discussion}

Badia and Iglesias (2019) claimed in a more recent study that participants of the flipped classroom are more invested in and motivated to participate. Though this study did not 
specifically ask the participants to provide a point of comparison, the participants stated that they have a higher level of motivation and engagement; this suggested that the flipped classroom bears an advantage compared to traditional methods. Similarly, the participants commented that the content presented is more appealing through the means of discussion with peers, which is identical to what Piaget (1976) claimed in his initial argument about cognitive constructivism theory. Furthermore, the participants stated that the option to actively contribute, higher motivation to prepare in advance, and the added benefit to learning from others are comparable to the claim from Badia et al. (2019), who argued that participants in flipped classroom courses have a higher degree of involvement and motivation compared to a traditional classroom, where a teacher would hold a lecture.

Nevertheless, the participants also stated limitations that affected their involvement in the flipped classroom course. The limitations and challenges are related to less flexibility in a noisy environment. The participants commented that, in order to actively engage and involve themselves in the flipped classroom, a quiet environment is needed with no distractions or background noises. Otherwise it was impossible to contribute, as this would disrupt the communication flow of others. Another limitation stated by the participants was the initial hesitation to involve themselves in the discussion (Fuchs, Aghaee and Ferati, 2020). One participant made a suitable claim that described the limitation in a very effective manner:

"It needs several sessions. It takes time to build that base and therefore you need a series of meetings [...] people need to know each other and feel comfortable [...]".

This key finding of the empirical data collection was not mentioned in any scientific publication, even though Piaget (1976) claimed in a related manner that constructivism theory requires a certain degree of trust amongst the participants. In another study about distance learning and online education, Dziuban et al. (2018) claimed that the lack of socialization in distance learning could be a potential factor that affects the students' learning outcomes.

To summarize the discussion, it can be stated that - based on Piaget's (1976) initial argument with regards to cognitive constructivism and the associated characteristics - the participants confirmed that the knowledge transfer that occurred through discussion-based sessions helped them to achieve better learning outcomes. Also, it was perceived as beneficial in their learning experience, as initially claimed through another study by Badia et al. (2019). The classroom design was perceived similarly to the design of Mukherjee et al. (2017), although the participants could not identify the post-class stage of the flipped classroom. Instead, the findings revealed that the discussion in the second stage was the most beneficial factor in advancing their knowledge, which was positively influenced by the pre-reading material from stage one. The fact that students were required to study the material in advance for the discussion led to a higher motivation to learn, which was perceived as positive. While the communication was claimed as an active two-way communication amongst peers during the discussion, a shortcoming was the initial hurdle to speak out; it took few sessions to overcome that barrier and achieve a pleasant study environment, which could be culturally related according to a study by Hutchison (2006). 


\section{Conclusion}

The ability to actively influence the outcome of the discussion and to benefit from the opinions of others was claimed by the participants as advantages to the TEFC, which is the basis for cognitive constructivism learning. However, there were shortcomings that were identified and addressed in this paper. It was claimed that the TEFC method would offer limited value to the participants if it were arranged as a one-off class or limited series. Instead, participants claimed that the flipped classroom concept required a series of meetings, wherein the initial meetings were perceived as more passive because participants were still overcoming the initial barrier to actively communicate while getting to know each other. Building a level of trust that enabled a more open discussion was a necessity. Furthermore, another identified limitation of the flipped classroom was the ability to actively contribute in a noisy environment. The participants described themselves as relatively active contributors in the discussion-based sessions and appreciated the ability to join these sessions from remote locations. However, it was addressed that the ability to contribute actively requires a quiet environment with no surrounding external noises, as this would disturb own learning and disrupt the discussion of others, as claimed by the participants. Based on the empirical findings of this research and the conclusions that were drawn, additional value would be added by expanding the scope of this study to include participants from different educational backgrounds and validate the results on a larger scale.

\section{Acknowledgment}

The author would like to whole-heartedly thank the participants who contributed to the research by attending the interview and sharing their experiences in these truly unique times. Moreover, the author would like to declare no potential conflicts of interest concerning the research, authorship, and/or publication of this article. The data collection originated and derived from a Master's thesis that the author collected personally.

\section{References}

Badia, A. and Iglesias, S., 2019. The science teacher identity and the use of technology in the classroom. Journal of Science Education and Technology, 28(5), pp.532-541. https://doi.org/10.1007/s10956-019-09784-w

Bishop, J.L. and Verleger, M.A., 2013, June. The flipped classroom: A survey of the research. In ASEE national conference proceedings, Atlanta, GA (Vol. 30, No. 9, pp. 1-18).

Creswell, J.W. and Creswell, J.D., 2017. Research design: Qualitative, quantitative, and mixed methods approaches. Sage publications, pp.34-72.

Crosslin, M., 2016. From instructivism to connectivism: theoretical underpinnings of MOOCs. Current Issues in Emerging eLearning, 3(1), p.6.

Davies, R.S., Dean, D.L. and Ball, N., 2013. Flipping the classroom and instructional technology integration in a college-level information systems spreadsheet course. Educational Technology Research and Development, 61(4), pp.563-580. https://doi.org/10.1007/s11423-013-9305-6 
Dewey, J.W., Wald, D.J., Quitoriano, V., and Dengler, L.A., 1999. Utilization of the Internet for rapid community intensity maps. Seismological Research Letters, 70(6), pp.680-697. https://doi.org/10.1785/gssrl.70.6.680

Dziuban, C., Graham, C.R., Moskal, P.D., Norberg, A. and Sicilia, N., 2018. Blended learning: the new normal and emerging technologies. Journal of Information Technology Research (JITR), 15(1), p.3. https://doi.org/10.1186/s41239-017-0087-5

Fuchs, K., Aghaee, N. and Ferati, M., 2020, November. Merits of the technology-enhanced flipped classroom (TEFC) concept in higher education. In Norsk IKT-konferanse for forskning og utdanning (No. 4).

Hutchison, C.B., 2006. Cultural constructivism: the confluence of cognition, knowledge creation, multiculturalism, and teaching. Intercultural Education, 17(3), pp.301-310. https://doi.org/10.1080/14675980600841694

Kim, M.K., Kim, S.M., Khera, O. and Getman, J., 2014. The experience of three flipped classrooms in an urban university: an exploration of design principles. The Internet and Higher Education, 22, pp.37-50. https://doi.org/10.1016/j.iheduc.2014.04.003

Li, M., Lai, C.W. and Szeto, W.M., 2019, May. Whiteboard Animations for Flipped Classrooms in a Common Core Science General Education Course. In Fifth International Conference on Higher Education Advances, p.127-133. https://doi.org/10.4995/HEAD19 .2019 .9250

McLaughlin, J.E., Roth, M.T., Glatt, D.M., Gharkholonarehe, N., Davidson, C.A., Griffin, L.M., Esserman, D.A. and Mumper, R.J., 2014. The flipped classroom: a course redesign to foster learning and engagement in professions school. Journal of Information Technology Research (JITR), 9(1), 89(2), pp.236-243. https://doi.org/10.1097/ACM.00000000000 $\underline{00086}$

Melzer, P., 2019. A conceptual framework for task and tool personalisation in IS education. In A Conceptual Framework for Personalised Learning (pp. 47-76). Springer Gabler, Wiesbaden. https://doi.org/10.1007/978-3-658-23095-1_3

Mukherjee, A. and Bleakney, S., 2017. Redesigning an Introduction to Informaton Systems Course for Scalable Active Learning in Online and Blended Environments. In Americas Conference on Information Systems (AMCIS). Association for Information Systems.

Olaniyi, N.E., 2020. Threshold concepts: designing a format for the flipped classroom as an active learning technique for crossing the threshold. Research and Practice in Technology Enhanced Learning, 15(1), p.2. https://doi.org/10.1186/s41039-020-0122-3

Piaget, J., 1976. Piaget's theory. In Piaget and his school (pp. 11-23). Springer, Berlin, Heidelberg. https://doi.org/10.1007/978-3-642-46323-5 2 


\section{Appendices}

Appendix 1.

Series of questions that were utilized during the interview

\begin{tabular}{|c|c|}
\hline Sequence & Questions \\
\hline Question 1 & Gender: (1) Male, (2) Female, (3) Others, (4) Prefer not to answer \\
\hline Question 2 & $\begin{array}{l}\text { Age Group: (1) } 20 \text { years or below, (2) } 21-29 \text { years, (3), } 30-39 \text { years, (4) } 40 \text { years or } \\
\text { above, (5) Prefer not to answer }\end{array}$ \\
\hline Question 3 & Your location: City \& Country \\
\hline Question 4 & $\begin{array}{l}\text { Educational Level: (1) Bachelor's degree, (2) Master's degree, (3) Others, please specify, } \\
\text { (4) Prefer not to answer }\end{array}$ \\
\hline Question 5 & Tuition paying student: (1) Yes, (2) No, (3) Prefer not to answer \\
\hline Question 6 & $\begin{array}{l}\text { Were you aware that the course would be conducted as flipped classroom before you } \\
\text { started the course? } \mathrm{A}=\mathrm{Yes}, \mathrm{B}=\mathrm{No}\end{array}$ \\
\hline Question 7 & $\begin{array}{l}\text { Would you describe yourself as active participant in the flipped classroom sessions? } 1= \\
\text { Disagree, } 2=\text { Somewhat disagree, } 3=\text { Neutral, } 4=\text { Somewhat agree, } 5=\text { Agree }\end{array}$ \\
\hline Question 8 & Do you prefer the flipped classroom classes or traditional classroom teaching and why? \\
\hline Question 9 & $\begin{array}{l}\text { How would you describe the flipped classroom sessions in your words based on your } \\
\text { experience? }\end{array}$ \\
\hline Question 10 & $\begin{array}{l}\text { Could you tell me about your experience or knowledge with the flipped classroom concept } \\
\text { before you started the course? }\end{array}$ \\
\hline Question 11 & $\begin{array}{l}\text { Where do you see the differences between the flipped classroom and traditional classroom } \\
\text { teaching? }\end{array}$ \\
\hline Question 12 & $\begin{array}{l}\text { How would you describe the communication between the students and teachers in the } \\
\text { flipped classroom sessions? }\end{array}$ \\
\hline Question 13 & $\begin{array}{l}\text { Does the interaction between teacher and student differ between pre-class, during class and } \\
\text { post-class and how? }\end{array}$ \\
\hline Question 14 & $\begin{array}{l}\text { Based on your earlier response about how you describe the flipped classroom, how does it } \\
\text { differ from the model that I sent you and where is the overlap? }\end{array}$ \\
\hline Question 15 & $\begin{array}{l}\text { Can you describe the Information and Communication Technologies (ICT) that you use in } \\
\text { pre-class, during class and post-class of your flipped classroom course? }\end{array}$ \\
\hline Question 16 & Which aspect of the ICT works well and which aspect could be improved? \\
\hline Question 17 & What kind of tool would add additional value and why? \\
\hline Question 18 & $\begin{array}{l}\text { How would you describe the communication with your peers (peer-to-peer) during class } \\
\text { and outside class for the flipped classroom course? }\end{array}$ \\
\hline
\end{tabular}

